
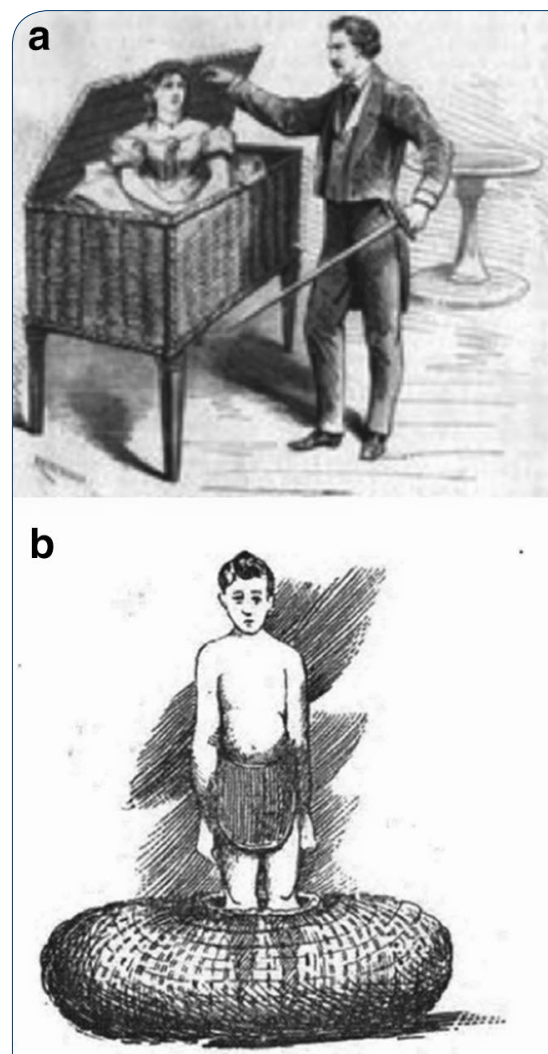
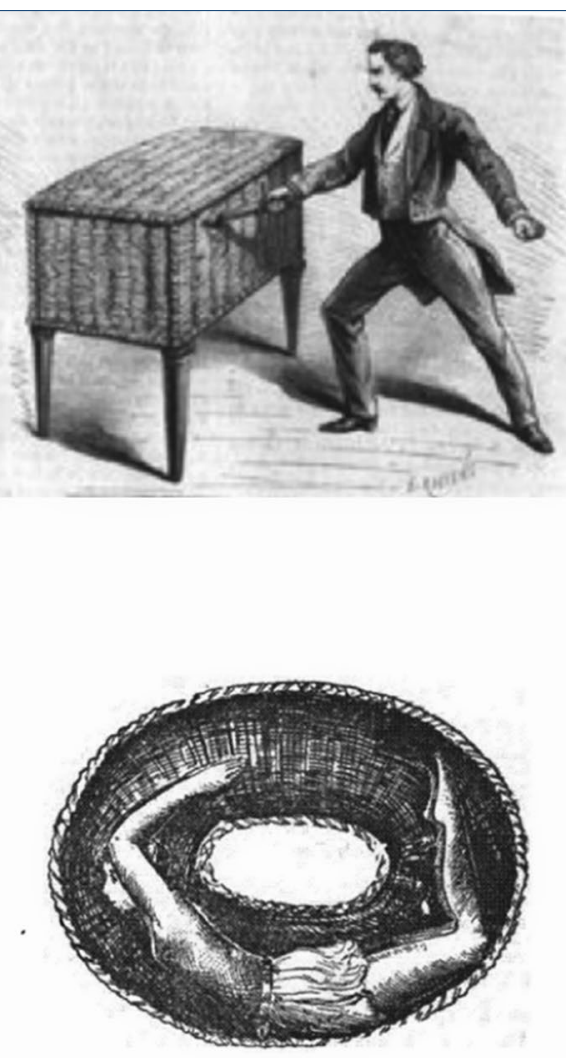

C THEATRE OF MYSTERY, FGYPTIAN HAII, TD-NICHIT, AND EVIRY EVENING IAT EIGET. Wednesday and Saturday Mornings at Three.

STODARE (WIDOW OF THE LATE COLONEL STODARE) FIRBANK BURMAN, COLONEL STODARE'S

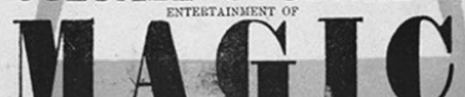

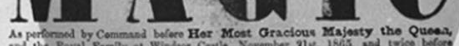

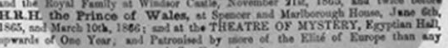
THE RENOWNED SPHINX, THE MARVEL OF MECCA, INDIAN BASKET TRICK,

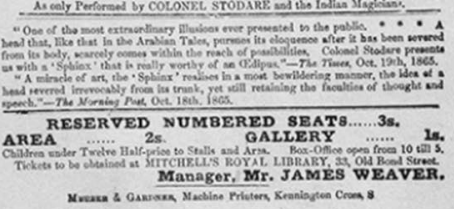

\title{
The Indian Basket Trick: a case of delayed paraplegia with complete recovery, caused by misplaced thoracic pedicle screw
}

Leroy et al.

垪 Springer Open 


\title{
The Indian Basket Trick: a case of delayed paraplegia with complete recovery, caused by misplaced thoracic pedicle screw
}

\author{
Antonin Leroy ${ }^{1}$, Reda Kabbaj ${ }^{1}$, Arnaud Dubory ${ }^{1}$, Manon Bachy ${ }^{1,2}$, Anne-Isabelle Vermersch ${ }^{3}$ \\ and Raphaël Vialle $e^{1,2^{*}}$
}

\begin{abstract}
Introduction: Pedicle screw fixation allows purchase of all three spinal columns without encroaching into the spinal canal improving fracture fixation, as well as deformity correction. Fortunately, neurologic injury associated with pedicle screw malposition is rare.

Case presentation: A 19-year-old boy was surgically treated for severe right thoracic scoliosis associated with a Chiari Type 1 malformation and a C6 to T7 syringomyelia. Six months after the initial surgery, the patient was referred to our institution after three weeks of gait disturbances and repeated falls. Imaging showed the gross misplacement of the left T5 pedicle screw, which crossed the center of the vertebral canal. The initial surgery used a freehand technique of pedicle screw insertion, with anteroposterior and lateral postoperative X-ray control. During the surgery, no SEP modifications were noted during pedicle screw placement. However, after insertion of the second rod and scoliosis correction by posterior translation technique, SEP responses decreased considerably. Revision surgery was performed to remove the misplaced screw. During the first three months after screw removal, repeated clinical examinations showed progressive recovery of the neurological deficits. Gait and bladder functions were normal six months after screw removal, and clinical signs of spasticity disappeared. SEP explorations performed at final follow-up showed similar responses to those performed before the initial surgery for scoliosis correction
\end{abstract}

Discussion and evaluation: Neurologic injury associated with pedicle screw malposition is rare. In early or delayed neurological status worsening, intraoperative or postoperative imaging must be done to detect pedicle screw misplacement. In the current case, thanks to cobalt-chromium and titanium use, MRI and CT scan allowed good visualization of the spinal canal and spinal cord. Experimental studies have shown that neurophysiological monitoring of the spinal cord does not detect moderate compression. In that way, neurophysiological monitoring is an all-or-nothing technique which can misdiagnose early stage of spinal cord injuries. Major penetration of the spinal canal by pedicle screw may conduct to hardware removal.

Conclusions: In early or delayed neurological status worsening, intraoperative or postoperative imaging must be done to detect pedicle screw misplacement. In the current case, thanks to cobalt-chromium and titanium use, MRI and CT scan allowed good visualization of the spinal canal and spinal cord. Major penetration of the spinal canal by pedicle screw may conduct to hardware removal.

Keywords: Misplaced pedicle screw, SEP monitoring, Scoliosis, Late paraplegia

\footnotetext{
*Correspondence: raphael.vialle@aphp.fr

1 Department of Pediatric Orthopaedics, Armand Trousseau Hospital,

Université Pierre et Marie Curie Paris6, 26 Avenue du Dr Arnold Netter,

75571 Paris Cedex 12, France

Full list of author information is available at the end of the article
} 


\section{Case report}

A 19-year-old boy was surgically treated for severe right thoracic scoliosis associated with a Chiari Type 1 malformation and a C6 to T7 syringomyelia. The Chiari Type 1 malformation was first operated on at the age of 14; the result was considered satisfactory, and the syringomyelia was considered stable between ages 14 and 19. Because Cobb angle increased to $95^{\circ}$ (Fig. 1a), the patient received surgical treatment for a T2 to L1 correction, with fusion by posterior approach. The patient underwent posterior spinal fusion and instrumentation, using an all-pedicle screw construct except for the two proximal levels, anchored by hooks. The construct was made using the CD HORIZON $^{\circledR}$ SOLERA $^{\mathrm{TM}}$ Spinal System (Medtronic, 710 Medtronic Parkway, Minneapolis, MN 55432-5604, USA) and two $5.5-\mathrm{mm}$ diameter cobalt-chromium rods. The patient was operated on by posterior approach on a Hall frame and with permanent sensory-evoked potential (SEP) monitoring. SEP monitoring protocol consisted in a continuous SEP monitoring with bilateral posterior tibial nerve stimulation and cortical and cervical detection. SEP amplitudes and latencies were recorded in a continuous fashion from patient positioning under general anaesthesia to the end of the surgical procedure.

The surgery used a freehand technique of pedicle screw insertion, with anteroposterior and lateral postoperative $\mathrm{X}$-ray control. During the surgery, no SEP modifications were noted during pedicle screw placement. However, after insertion of the second rod and scoliosis correction by posterior translation technique, SEP responses decreased considerably. SEP amplitudes decreased $90 \%$, while latencies increased significantly (Fig. 2). A subsequent wake-up test showed a complete absence of motor function in both lower limbs. The decision was made to decrease the intensity of correction by contouring the rods (Fig. 1b). This maneuver resulted in improved, but still decreased by $75 \%$ SEP amplitudes and normal (i.e. similar to baseline values) latencies responses, and the patient exhibited no motor or sensory deficit after the procedure. Intraoperative fluoroscopy imaging did not demonstrate any concern for hardware. Daily clinical examinations performed during the first postoperative week showed no motor or sensory deficit. No bowel dysfunction or incontinence were noted during the postoperative course. The details of SEP monitoring values are reported in Table 1.

Six months after the initial surgery, the patient was referred to our institution after 3 weeks of gait disturbances and repeated falls. Clinical examination showed weakness $(4 / 5)$ of the right psoas, the right flexor digitorum profundus, and the right triceps. There was a right Babinsky sign with increased deep tendon reflexes in both lower limbs. Romberg sign was positive. The patient also presented severe dysuria with bladder distention requiring urinary catheter. There was no recent history trauma, no fever and no remaining biological sign of infection. Axial, sagittal and coronal planes of a thoracolumbar CT scan confirmed the gross misplacement of the pedicle screw,

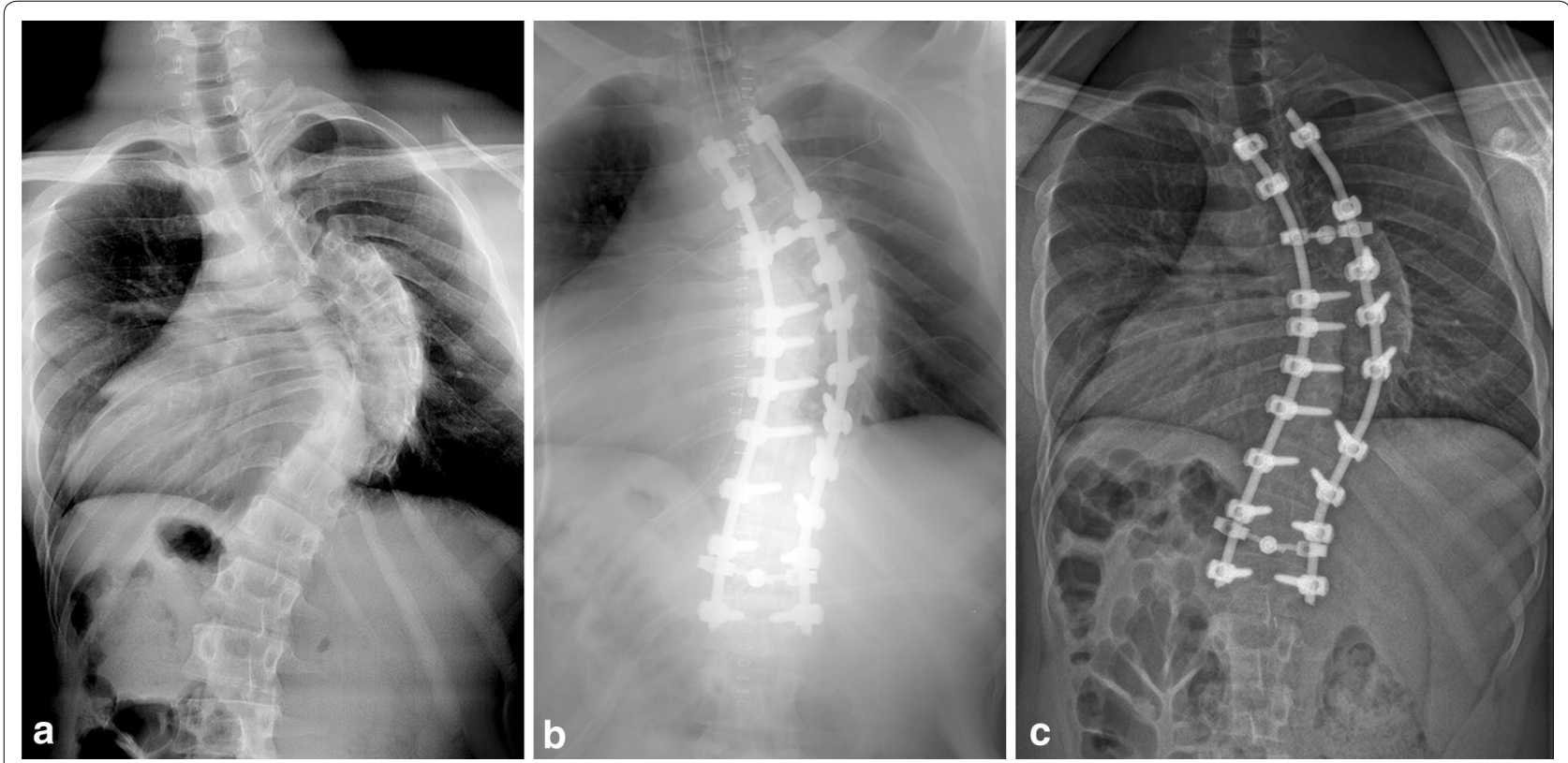

Fig. 1 a Preoperative frontal X-ray of the right $95^{\circ}$ thoracic scoliosis. b Postoperative frontal X-ray after index procedure. c Postoperative frontal $\mathrm{X}$-ray after revision procedure and screw removal 


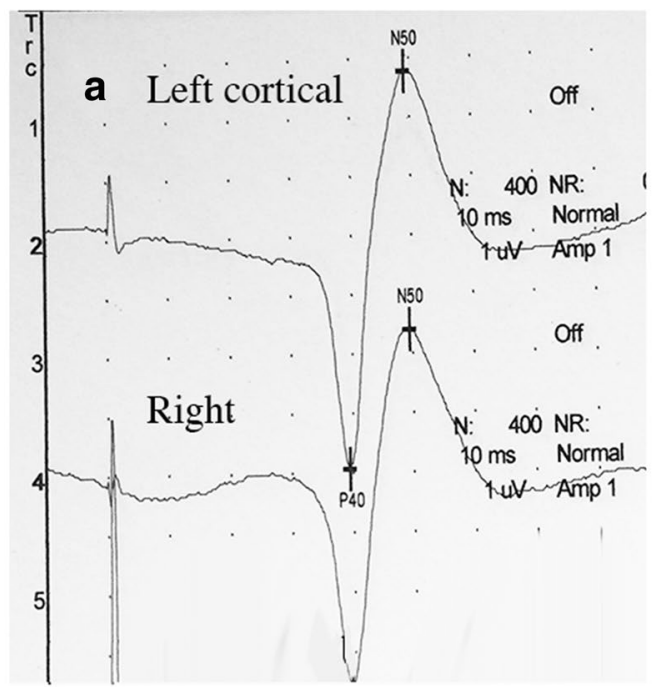

During pedicle screws placement

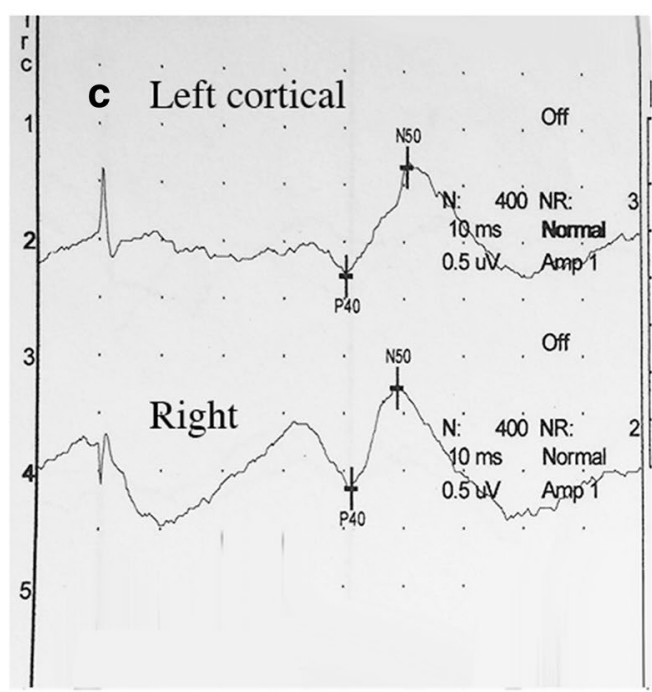

After second rod insertion

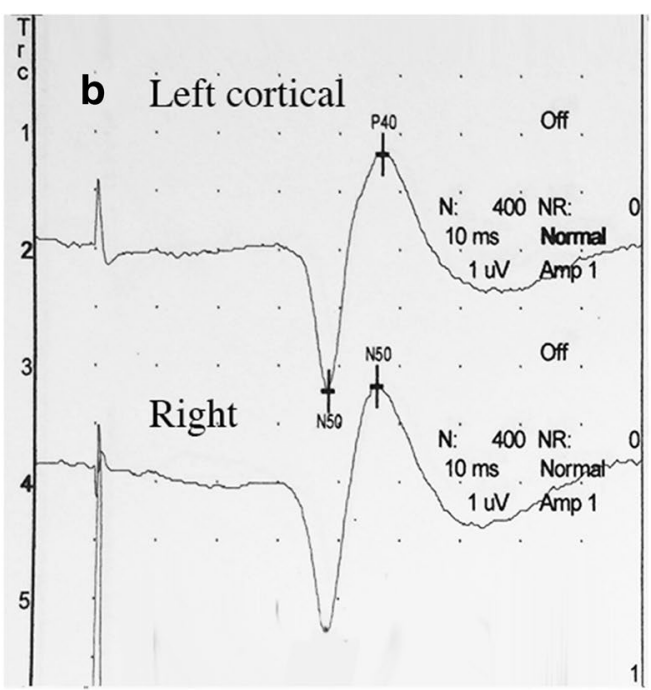

During first rod insertion

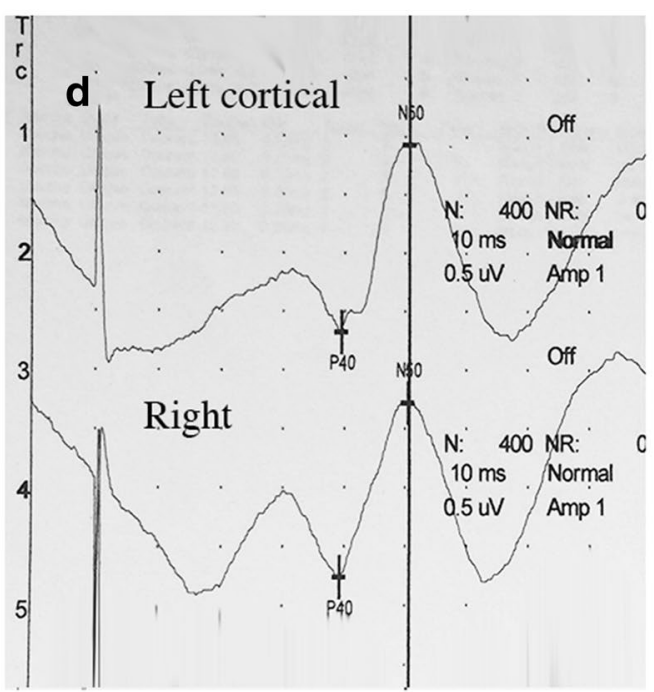

End of the surgery

\section{and curve correction}

Fig. 2 Results of sensitive evoked potentials (SEP) after stimulation of both posterior tibial nerves at various times of the surgery. a Results during screws placement, $\mathbf{b}$ results during first rod insertion, $\mathbf{c}$ results during second rod insertion and spinal curve correction showing a decrease of cortical amplitudes and increase of latencies, $\mathbf{d}$ results at the end of the surgical procedure with improved amplitudes and normal latencies

Table 1 Details of SEP monitoring during index procedure

\begin{tabular}{llcccc}
\hline & & Screws placement & First rod insertion & $\begin{array}{l}\text { Second rod insertion and spinal } \\
\text { curve correction }\end{array}$ & $\begin{array}{c}\text { End of the } \\
\text { surgery }\end{array}$ \\
\hline Left cortical & Amplitude $(\mu \mathrm{V})$ & 6.75 & 4.16 & 0.98 & 1.62 \\
& Latency P40 $(\mathrm{ms})$ & 39.4 & 47.0 & 40.3 & 39.4 \\
& Latency N50 (ms) & 49.0 & 38.2 & 50.4 & 50.7 \\
Right cortical & Amplitude $(\mu \mathrm{V})$ & 6.01 & 4.34 & 41.2 & 1.51 \\
& Latency P40 (ms) & 39.5 & 38.1 & 48.9 & 39.3 \\
& Latency N50 (ms) & 49.4 & 46.2 & 50.4 \\
\hline
\end{tabular}


which crossed the center of the vertebral canal (Fig. 3a-c). Spinal MRI was performed to check the C6 to T7 syringomyelia, which showed an increased diameter of the syrinx adjacent to a left $\mathrm{T} 5$ pedicle screw crossing the spinal canal (Fig. 3d). SEP monitoring showed altered responses, with decreased amplitudes and increased latencies (Fig. 4).

Revision surgery was performed to remove the misplaced screw. No spinal canal exploration was performed at this time. No cerebrospinal fluid effusion was noted during screw removal, and no meningocele occurred postoperatively. During the first 3 months after screw removal, repeated clinical examinations showed progressive recovery of the neurological deficits. Gait and bladder functions were normal 6 months after screw removal, and clinical signs of spasticity disappeared. The patient reported no motor or sensory deficit at final follow-up,
18 months after screw removal. SEP explorations performed at final follow-up showed similar responses to those performed before the initial surgery for scoliosis correction (Fig. 4), and final MRI confirmed the stability of syringomyelia. No loss of correction was noted after the revision procedure. Final follow-up radiographs showed a partially corrected deformity with good global spinal balance and satisfactory functional results. The patient gave his consent for the use of his personal and medical informations for the publication of this case report and any accompanying images.

\section{Discussion}

Pedicle screw fixation allows purchase of all three spinal columns without encroaching into the spinal canal. This theoretical advantage has been translated to superior
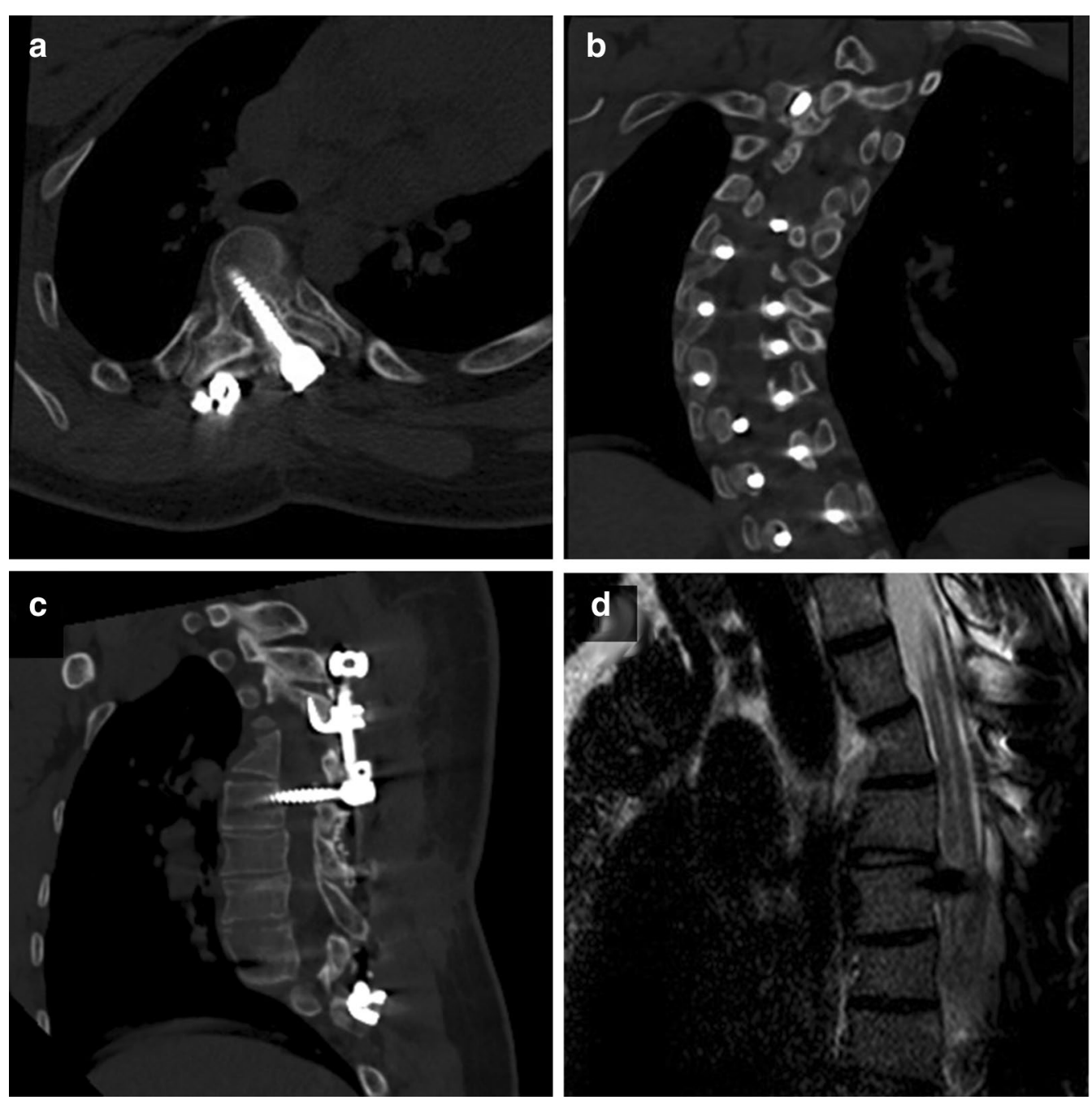

Fig. 3 CT scan showing the gross misplacement of the pedicle screw, which crossed the center of the vertebral canal on axial (a), coronal (b) and sagittal (c) planes. $\mathbf{d}$ Same sagittal plane of spinal MRI showing an increased diameter of the syrinx adjacent to a left T5 pedicle screw crossing the spinal canal 


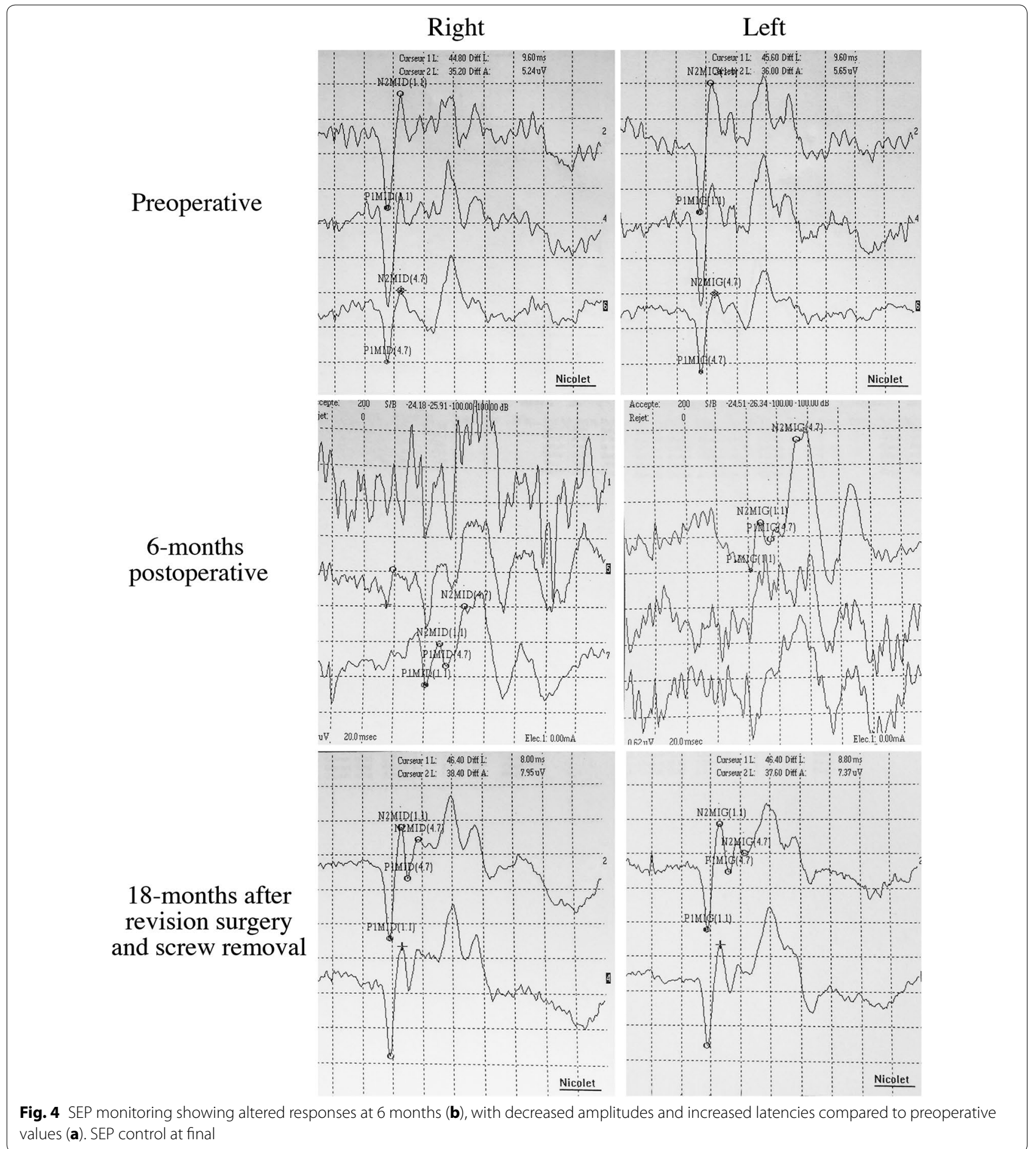

clinical results in fracture fixation, as well as in deformity correction (Dickman et al. 1994; Dobbs et al. 2006; Kim et al. 2006; Payer 2005; Yue et al. 2002). For years, introduction of newer techniques, such as fluoroscopically assisted navigation, has lowered pedicle perforation rates (Bransford et al. 2006; Rajasekaran et al. 2007), allowing experienced hands to safely place pedicle screws within the thoracic spine (Hyun et al. 2012; Karapinar et al. 2008; Kim et al. 2004; Vialle et al. 2014; Samdani et al. 2010). Suk et al. (Suk et al. 2001) evaluated more than 4000 thoracic pedicle screws and found a malposition rate of $1.5 \%$. 
Fortunately, neurologic injury associated with pedicle screw malposition is rare. One author evaluated 3204 screws and reported no vascular, neurologic or visceral injuries (Kim et al. 2004). A second author reported a rate of $0.8 \%$ and noted the greatest risk to be on the concave side of the deformity (Suk et al. 2001). This finding is consistent in the literature (Hicks et al. 2010) and suggests that a significant degree of medullary displacement and/or compression is necessary to produce neurophysiological changes (Wadouh et al. 1985; Feng et al. 2014). In early or delayed neurological status worsening, intraoperative or postoperative imaging must be done to detect pedicle screw misplacement. In the current case, thanks to cobalt-chromium and titanium use, MRI and CT scan allowed good visualization of the spinal canal and spinal cord. Major penetration of the spinal canal by pedicle screw may conduct to hardware removal.

\section{Improving safety}

Routine MEP after insertion of each pedicle screw in the thoracic spine, as well as triggered EMG stimulation of each pedicle screw to rule out breaching once all screws have been inserted, could improve safety in challenging cases (Calancie et al. 2014a, b). As in the present case, according to several clinical studies (Danesh-Clough et al. 2001; Raynor et al. 2002; Reidy et al. 2001; Rodriguez-Olaverri et al. 2008; Shi et al. 2003), current intraoperative neurophysiological monitoring techniques do not always accurately reveal the presence of thoracic pedicle screws within the spinal canal. Experimental studies have shown that neurophysiological monitoring of the spinal cord does not detect moderate compression. In that way, neurophysiological monitoring is an all-or-nothing technique which can misdiagnose early stage of spinal cord injuries. Also, a significant delay in identifying the lesion reduces response time to reverse the damage by removing the incorrectly positioned implants (Feng et al. 2014; Flynn and Sakai 2013).

As patient safety becomes more and more of a concern, the use of intraoperative CT scanning, with real CT imaging or CT fluoroscopy of pedicle screws post-insertion, may become a standard of care in the future (Flynn and Sakai 2013).

Some technical tricks, such as the funnel technique (Gaines 2000), allow direct visualization of the entrance into the pedicle, as well as its direction, without the problems mentioned earlier. Two papers have been published evaluating the safety of the funnel technique (Viau et al. 2002; Yingsakmonkol et al. 2002). Because complex spinal deformity distorts anatomic landmarks, we stress the importance of such alternative technique as the "slide technique" as an improvement of the funnel technique (Vialle et al. 2014). The slide technique is a freehand technique for thoracic pedicle screw placement that passes through the decancelled transverse process could be satisfactory and helpful in our clinical experience, especially in severe thoracic spinal deformities. Unfortunately, this technical trick was not used in the current case and might have avoided the initial medial breach.

\section{Conclusions}

This uncommon case of completely misplaced pedicle screw crossing the spinal canal draw the reader's attention to the risk of pedicle screw placement in severe thoracic curves. In case of early or delayed neurological status worsening, intraoperative or postoperative imaging must be done to detect pedicle screw misplacement. In the current case, thanks to cobalt-chromium and titanium use, MRI and CT scan allowed good visualization of the spinal canal and spinal cord. Major penetration of the spinal canal by pedicle screw may conduct to hardware removal.

\section{Authors' contributions}

AL was responsible for collecting the data. RK was responsible for writing the manuscript. $A D$ was responsible for writing and editing the manuscript. $M B$ was responsible for collecting and editing the data and iconography. AV was responsible for collecting the neurophysiological monitoring elements. RV was responsible for publication supervision, editing the data and submission process. All authors read and approved the final manuscript.

\section{Author details}

${ }^{1}$ Department of Pediatric Orthopaedics, Armand Trousseau Hospital, Université Pierre et Marie Curie Paris6, 26 Avenue du Dr Arnold Netter, 75571 Paris Cedex 12, France. ${ }^{2}$ Department for Innovative Therapies in Musculoskeletal Diseases, Armand Trousseau Hospital, The MAMUTH Hospital-University, 26, Avenue du Docteur Arnold Netter, 75571 Paris Cedex 12, France. ${ }^{3}$ Department of Pediatric Neuro-Monitoring, Armand Trousseau Hospital, Université Pierre et Marie Curie Paris6, 26 Avenue du Dr Arnold Netter, 75571 Paris Cedex 12, France.

\section{Competing interests}

RV works as a consultant for Stryker Spine. No other authors have potential conflicts of interest regarding the submitted work.

\section{Funding disclosure}

No funding from National Institutes of Health (NIH), Welcome Trust, Howard Hughes Medical Institute (HHMI).

Received: 8 March 2016 Accepted: 11 May 2016

Published online: 30 June 2016

\footnotetext{
References

Bransford R, Bellabarba C, Thompson JH et al (2006) The safety of fluoroscopically-assisted thoracic pedicle screw instrumentation for spine trauma. J Trauma 60:1047-1052. doi:10.1097/01.ta.0000215949.95089.18

Calancie B, Donohue ML, Moquin RR (2014a) Neuromonitoring with pulsetrain stimulation for implantation of thoracic pedicle screws: a blinded and randomized clinical study. Part 2. The role of feedback. J Neurosurg Spine 20:692-704. doi:10.3171/2014.2.SPINE13649

Calancie B, Donohue ML, Harris CB et al (2014b) Neuromonitoring with pulsetrain stimulation for implantation of thoracic pedicle screws: a blinded and randomized clinical study. Part 1. Methods and alarm criteria. J Neurosurg Spine 20:675-691. doi:10.3171/2014.2.SPINE13648
} 
Danesh-Clough T, Taylor P, Hodgson B, Walton M (2001) The use of evoked EMG in detecting misplaced thoracolumbar pedicle screws. Spine 26:1313-1316

Dickman CA, Yahiro MA, Lu HT, Melkerson MN (1994) Surgical treatment alternatives for fixation of unstable fractures of the thoracic and lumbar spine. A meta-analysis. Spine 19:2266S-2273S

Dobbs MB, Lenke LG, Kim YJ et al (2006) Selective posterior thoracic fusions for adolescent idiopathic scoliosis: comparison of hooks versus pedicle screws. Spine 31:2400-2404. doi:10.1097/01.brs.0000240212.31241.8e

Feng B, Shen J, Zhang J et al (2014) How to deal with cerebrospinal fluid leak during pedicle screw fixation in spinal deformities surgery with intraoperative neuromonitoring change. Spine 39:E20-E25. doi:10.1097/ BRS.0000000000000058

Flynn JM, Sakai DS (2013) Improving safety in spinal deformity surgery: advances in navigation and neurologic monitoring. Eur Spine J Off Publ Eur Spine Soc Eur Spinal Deform Soc Eur Sect Cerv Spine Res Soc 22(Suppl 2):S131-S137. doi:10.1007/s00586-012-2360-6

Gaines RW (2000) The use of pedicle-screw internal fixation for the operative treatment of spinal disorders. J Bone Joint Surg Am 82-A:1458-1476

Hicks JM, Singla A, Shen FH, Arlet V (2010) Complications of pedicle screw fixation in scoliosis surgery: a systematic review. Spine 35:E465-E470. doi:10.1097/BRS.0b013e3181d1021a

Hyun S-J, Kim YJ, Cheh G et al (2012) Free hand pedicle screw placement in the thoracic spine without any radiographic guidance: technical note, a cadaveric study. J Korean Neurosurg Soc 51:66-70. doi:10.3340/ jkns.2012.51.1.66

Karapinar L, Erel N, Ozturk H et al (2008) Pedicle screw placement with a free hand technique in thoracolumbar spine: is it safe? I Spinal Disord Tech 21:63-67. doi:10.1097/BSD.0b013e3181453dc6

Kim YJ, Lenke LG, Bridwell KH et al (2004) Free hand pedicle screw placement in the thoracic spine: is it safe? Spine 29:333-342 (discussion 342)

Kim YJ, Lenke LG, Kim J et al (2006) Comparative analysis of pedicle screw versus hybrid instrumentation in posterior spinal fusion of adolescent idiopathic scoliosis. Spine 31:291-298. doi:10.1097/01.brs.0000197865.20803. $\mathrm{d} 4$

Payer M (2005) Unstable upper and middle thoracic fractures. Preliminary experience with a posterior transpedicular correction-fixation technique. J Clin Neurosci Off J Neurosurg Soc Australas 12:529-533. doi:10.1016/j. jocn.2004.11.006
Rajasekaran S, Vidyadhara S, Ramesh P, Shetty AP (2007) Randomized clinical study to compare the accuracy of navigated and non-navigated thoracic pedicle screws in deformity correction surgeries. Spine 32:E56-E64. doi:10.1097/01.brs.0000252094.64857.ab

Raynor BL, Lenke LG, Kim Y et al (2002) Can triggered electromyograph thresholds predict safe thoracic pedicle screw placement? Spine 27:2030-2035

Reidy DP, Houlden D, Nolan PC et al (2001) Evaluation of electromyographic monitoring during insertion of thoracic pedicle screws. J Bone Joint Surg Br 83:1009-1014

Rodriguez-Olaverri JC, Zimick NC, Merola A et al (2008) Using triggered electromyographic threshold in the intercostal muscles to evaluate the accuracy of upper thoracic pedicle screw placement (T3-T6). Spine 33:E194-E197. doi:10.1097/BRS.0b013e3181696094

Samdani AF, Ranade A, Saldanha V, Yondorf MZ (2010) Learning curve for placement of thoracic pedicle screws in the deformed spine. Neurosurgery 66:290-294. doi:10.1227/01.NEU.0000363853.62897.94 (discussion 294-295)

Shi Y, Binette M, Martin WH et al (2003) Electrical stimulation for intraoperative evaluation of thoracic pedicle screw placement. Spine 28:595-601. doi:10.1097/01.BRS.0000049926.43292.93

Suk SI, Kim WJ, Lee SM et al (2001) Thoracic pedicle screw fixation in spinal deformities: are they really safe? Spine 26:2049-2057

Vialle R, Zeller R, Gaines RW (2014) The "slide technique": an improvement on the "funnel technique" for safe pedicle screw placement in the thoracic spine. Eur Spine J Off Publ Eur Spine Soc Eur Spinal Deform Soc Eur Sect Cerv Spine Res Soc. doi:10.1007/s00586-014-3342-7

Viau M, Tarbox BB, Wonglertsiri S et al (2002) Thoracic pedicle screw instrumentation using the "Funnel Technique": part 2. Clinical experience. J Spinal Disord Tech 15:450-453

Wadouh F, Arndt CF, Metzger H et al (1985) Direct measurements of oxygen tension on the spinal cord surface of pigs after occlusion of the descending aorta. J Thorac Cardiovasc Surg 89:787-794

Yingsakmonkol W, Karaikovic E, Gaines RW (2002) The accuracy of pedicle screw placement in the thoracic spine using the "Funnel Technique": part 1. A cadaveric study. J Spinal Disord Tech 15:445-449

Yue JJ, Sossan A, Selgrath C et al (2002) The treatment of unstable thoracic spine fractures with transpedicular screw instrumentation: a 3-year consecutive series. Spine 27:2782-2787. doi:10.1097/01. BRS.0000035727.46428.BE

\section{Submit your manuscript to a SpringerOpen ${ }^{\circ}$ journal and benefit from:}

- Convenient online submission

- Rigorous peer review

- Immediate publication on acceptance

- Open access: articles freely available online

- High visibility within the field

- Retaining the copyright to your article

Submit your next manuscript at $\boldsymbol{\nabla}$ springeropen.com 